\title{
Paper Title: Visualising everyday ethnicity: moving beyond stereotypes of Roma minorities
}

Author details: ANNABEL TREMLETT is Senior Lecturer in the School of Health Sciences and Social Work at the University of Portsmouth.

ADDRESS: School of Health Sciences and Social Work, University of Portsmouth, James Watson West, 2 King Richard $1^{\text {st }}$ Road, Portsmouth. PO1 2FR, UK. Email: annabel.tremlett@port.ac.uk

\section{Publication details:}

To appear in 'Romaphobia and the Media', a special issue of Identities journal edited by Annabel Tremlett, Vera Messing and Angéla Kóczé 2017. Journal issue due out December 2017 (volume 24, issue 6). 


\title{
Visualising everyday ethnicity: moving beyond stereotypes of Roma minorities
}

\section{by Annabel Tremlett (University of Portsmouth, UK)}

\begin{abstract}
The visual image of Roma people in the media is mired in racialised notions of 'the other'. Whilst we know what Roma stereotypes look like, there is little clarity as to how a 'nonstereotypical' image might be constructed. In order to examine the non-stereotypical, two sources of images are analysed: (i) entrants from an anti-stereotype Roma photography competition and (ii) self-representations produced by Roma participants during ethnographic research. The findings show that if 'Roma' is foregrounded as the subject, even a nonstereotypical approach can reproduce 'difference' (from a supposed 'norm'). 'Roma' is thus, at the moment, still strongly linked to a notion of ethnicity that is seen as different and racialised. However, when ethnicity is not emphasised, but rather self-representations and the 'everyday', such orthodoxies are challenged. These sources provide a unique opportunity to create a deeper understanding of 'non-stereotypical' images in order to challenge misrepresentations and racism.
\end{abstract}

\section{Keywords:}

Photo elicitation; Roma; stereotype; everyday; representations; racism.

\section{Introduction}

Roma/Gypsy ${ }^{\mathrm{i}}$ people in Europe are trapped by stereotypical portrayals. On the one hand, they are commonly depicted as simply victims of the racism from which they have historically suffered. On the other, they are often chastised for their chronic poverty, alleged 'lack' of civilisation, criminality, bad fit with modern life and backwardness. Those who want to counteract such racism or deficit portrayals have tended to respond with claims about the special value attached to Roma culture and the Roma way of life. The visual image of 'the Roma' has been central to these portrayals, as Gay y Blasco writes: "They are the objects of both revulsion and fascination and have, through the centuries, been pictured, narrated and 'known' ad nauseam" (2008, 297). A Manichean frame is created: Roma people are either pitied or chastised, their cultural practices venerated or denigrated. Each of these crude stances, in their own ways, disallow Roma people their full humanity. This article asks questions rarely approached in academia: What might a 'non-stereotypical' image of Roma look like? How can this be achieved? ?i $^{\mathrm{i}}$

This article begins by giving an overview of the importance placed on the visual for the representation of Roma minorities and how 'stereotypes' are formed. In the search for nonstereotypical images, the article then considers two sources of pictures: the first source is from the entrants of a Europe-wide photography competition Chachipe (meaning 'truth', 'reality' 
or 'right' in Romanes) that stipulates "non-stereotypical photographs that are free of prejudices" [sic http://chachipe.org]. The analysis shows that even a 'non-stereotypical' approach can still result in reproducing certain stereotypes. The second source of images were not produced under the rubric of 'Roma', but rather from the 'everyday', drawn from ethnography and photo-elicitation (in which participants are asked to take their own images) with seven young Roma people in Hungary (aged 19-21 years of age) in 2013 $3^{\mathrm{iii}}$. This source offers an understanding of how the young people in the research visualise and describe their everyday lives. The article concludes by arguing that at this point in time, 'Roma' is still weighted in an archaic notion of ethnicity based on racist, essentialist ideas of 'race'. However, ethnographically sourced images show that if ethnicity is not stressed, but rather self-representations and 'the everyday', then a different image of Roma lives can emerge, one that may pave the way for 'non-stereotypical' representations of Roma.

\section{Conceptual framework: visualising the everyday as 'breaking the silence' of racism}

When writing about the image of the Caribbean in Europe, Stuart Hall talks about the Présence Européenne that constructs an idea of 'difference' used under colonialism (referring to Said's 1978 notion of 'the other') based on "exclusion, imposition and expropriation" (Hall 1990, 233). Whilst the history of Roma in Europe is particular, and many countries where Roma people reside (e.g. Central and Eastern Europe) do not have direct links to colonialism, nonetheless the 'dominant regimes' Hall lists below can be directly related to how Roma have been represented in European societies (see Imre 2005, Picker et al 2015, Trehan and Kóczé 2009):

[...]the European presence is that which, in visual representation, has positioned the black subject within its dominant regimes of representation: the colonial discourse, the literatures of adventure and exploration, the romance of the exotic, the ethnographic and travelling eye, the romance languages of tourism, travel brochure and Hollywood and the violent, pornographic languages of ganja and urban violence (Hall 1990, 233)

Visual images are "iconic" signs, that is, the image "reproduces some of the actual conditions of our visual perception in the visual sign" (Hall 1997, 7). The visual perception of Roma has, over time, became enmeshed with a certain iconic image that is based on a 'Gypsy fetish' described by Gay y Blasco as a “shared exotic imagination” (2008, 298). This 'Gypsy fetish' is complex in its universality and particularity. There are very strongly recognisable 'Gypsy' 
images, yet locally produced images also have their own specific inflections in the context of the politics/environment of the time.

This article uses broad terms that do not necessarily pick up on the nuances of representations. The word 'stereotypical' is used to describe stark, crude representations of Roma. At the same time, we know that many stereotypes are banal, subtle and will depend as much on the context, viewer and positioning of the image as it does on the image itself (see End's article, this volume). Similarly, the article uses the terms 'Roma' and 'non-Roma' in full awareness that they evoke generalised, inadequate binary oppositions: 'non Roma' assumes a norm, the 'unmarked' from which 'Roma' is different. Furthermore, the audience is not considered here when we know that the context and positioning of images works to produce meaning, just as much as an image works to affect the audience. The justification for taking such a rudimentary view is because of the ubiquity and longevity of certain strong stereotypes of Roma; the endurance of 'Roma' and 'non-Roma' as binary oppositions (in what Hall calls the "racialised regime of representation" 1997, 247); and how much public space is taken up with such broad labelling and stereotypes.

Stereotypes become a form of power and control as identities are given essential qualities, which are then hard to disqualify as they "invoke a consensus" (Dyer 2002, 14). However, whilst we have some ideas of what stereotypical images of Roma look like, this does not mean that the direct opposite is therefore 'non-stereotypical'. Moving away from stereotypes is not an oppositional process: as Gilroy says, anti-racist movements often fail as they use "narrow categories" that mirror the reductionist categories deployed by racist ideologies themselves (Gilroy 2002, 249). In understanding images of Roma minorities this is particularly important: academics have tried to show the 'other' side to Roma culture, but have been criticized for over-praising or over emphasizing certain 'positive' aspects of Roma identity that can simply create more stereotypes. Focusing on celebratory characteristics can still give a narrow view of a person's life, and although it may seem to acclaim the person in question, it just replaces the 'badge of stigma' with a 'badge of honour', which remains simplified and generalised (Pieterse 1992, 12).

One way to move away from this Manichean frame of 'the Roma' is not to reduce representations to either stigma or honour, but make a theoretical and methodological move to the everyday. The notion of 'the everyday' is used as a conceptual shift in ethnicity studies to 
move beyond the rhetoric of "nationally framed, fixed and abstract models of identity" (Clayton 2009: 482). In this article I use the term 'everyday' to mean the practices that people engage with on a day to day basis. For example, Brubaker's research on Roma minorities in Transylvania recognised the necessity of understanding lived realities in order to "capture the way ethnicity actually 'works"' (2006, xiv). The term 'ordinary', to use Highmore's definition, then brings a sense of collectivity, a sense of 'us':

Whilst the everyday might be an endless succession of singularities it is not helpful to understand it as peopled by monads. The ordinary harbours an abundance that is distinct from material plenty: it is there when we talk about something as common, it is there when we talk about society, and it is there when we talk about 'us'. The ordinary brings with it one of the most optimistic but also most daunting phrases from science fiction and horror: you are not alone (Highmore 2011, 5)

Of course, one person's ordinary can another person's extraordinary (Robinson 2015, 916). What we can do is look at how people might perceive 'ordinariness' and everyday practices themselves, a call to look at a "world where most of the time 'there is nothing to write home about" (Highmore 2011, 37) in order to understand how "lives are made livable in the midst of the social damage produced by widening class divisions" (Back 2015, 820).

Such everyday aspects of life can be powerfully captured by images (Mitchell 2011, Rose 2016, Stanczak 2007). Documentary photographer Stuart Franklin (who took the famous 'Tank Man' picture in Tiananmen Square in 1989) writes about how a focus on the everyday follows anti-essentialist theorisations through 'breaking the silence' of images that perpetuate racism,

[...] an anti-essentialist approach to documentary photography may be one that actively sets out to break the silence. It neither creates nor upholds myths or Edenic narratives. Instead, photography can and has been used to counter fixed and stereotypical views about race and racism in order to foster greater understanding while still embodying a creative treatment of reality (Franklin 2016, 48)

This approach of viewing photography as an anti-essentialist opportunity to "counter fixed and stereotypical views" of Roma is the one taken in this article. In my own work I have argued that researching Roma populations in the current climate requires "a careful de- 
essentialisation of the debates without losing sight of ethnicity" (Tremlett 2014, 845, see also $2009,165)$ as well as an understanding of the hybridity of Roma people (Tremlett 2009). This approach, similar to Franklin's, uses theories of anti-essentialism as a means to deconstruct dominant discourses and stereotypes. In this article the 'everyday' is used as an antiessentialist approach to look at the possibilities there are for more varied (non-stereotypical) visual images of Roma.

\section{Methodology}

The rationale for choosing the two sources of images was to analyse images that took a specifically 'anti-stereotype' approach that also focused on lived realities of Roma people (i.e. their everyday lives). In this section I outline my rationale for choosing these images and the methodological approach in collating and analysing them.

\section{Source 1: Photographs from the competition Chachipe}

The Chachipe photographic competition, run by the Open Society Foundations and the Open Society Archives at the Central European University, ran in 2007, 2009 and 2011 with the explicit goal of attracting "photos that would help combat visual stereotypes associated with Roma as well as sensitively and artistically present the everyday lives of Roma people,"iv from countries participating in the 'Decade of Roma Inclusion' (2005-2015) including Albania, Bulgaria, Bosnia and Herzegovina, Croatia, the Czech Republic, Hungary, Macedonia, Montenegro, Romania, Serbia, Slovakia and Spain:

We are seeking non-stereotypical photographs that are free of prejudices [sic], that show Roma and non-Roma living together, that approach topics in an open manner and that might even employ radically new perspectives (from the website http://chachipe.org, accessed February 11 2016).

I had noted the Chachipe competition during my time in Hungary and I was impressed by the winning entries, thinking it was an excellent way to challenge some of the predominant stereotypes in the public sphere. When carrying out research for this article, I thought I would just include a few of the winning images in an introduction as evidence of how an 'antistereotype' and 'everyday' approach could work. However, I noticed how not just the winning entries, but all entries to the competition were available online. This became a unique opportunity to look at how entrants (who were encouraged from Roma backgrounds, although 
ethnic backgrounds of entrants are not documented anywhere) from across 12 European countries envisaged the 'non-stereotypical' when it came to the Roma.

I had intended to carry out an analysis on all the entrants from across the three years the contest was run. This was a total of nearly 4000 photographs. Unfortunately, it appears the site was shut down on October $10^{\text {th }} 2016$ and I had to make do with the $1530 \mathrm{I}$ had accessed up to that point. The photographs did not appear to be in any particular order on the online database and I have accessed photographs from all three competitions and from entrants from 12 different countries. The analysis of the 1530 photographs cannot be seen as indicative or a criticism of the Chachipe competition as a whole (the organisers had no control over who entered), but what they can do is give an indication of how entrants envisaged antistereotypical images of Roma in everyday life. Due to copyright restrictions, the photographs from Chachipe cannot be shown in this article.

\section{Source 2: Photographs from ethnographic research}

In my own research I use ethnography and 'the everyday' in my approach to understanding the lived realities of Roma (and non-Roma) people from childhood to young adulthood in a Hungarian town. In this research I use the method of 'photo elicitation' which involves the researcher and participant sitting together with the photographs taken by the participant, trying to make sense of the images in a 'photo elicitation interview' (for an overview see Harper 2002, Rose 2016, 307-329). Photo elicitation can be used as a means to put more of the power into the hands of the researched (Clark-Ibáňez 2007, 1513; Harper 2012, 155-157). This approach was especially useful to me in my status as an adult researcher and 'less-thanfluent' Hungarian speaker, and the complex power relations these positionings bring (Tremlett 2009, 2013).

The 262 photographs analysed for this article were taken by seven young Roma adults, five women and two men, aged 19-21, in 2013 ${ }^{\mathrm{v}}$. I have known all of the participants since 2000 (when they were about 6-8 years old). Whilst the town they live in is relatively wealthy, the suburbs trail off into the Great Hungarian Plains and inequality is stark. All the participants in this project were from low socio-economic backgrounds. Five participants (Katalin, Adrienn, Laci, Zsófia, Szabina) had young children (one single mother - Szabina), two were single without children (Ágnes and István). Two of the participants lived with their partners and children by themselves in Dombos (Katalin and Zsófia), the others still lived in the family 
home with their parents. Two participants (Laci and Katalin) had ethnic Hungarian (nonRoma) partners. Six of the seven lived in two adjoining suburbs of Dombos, with one suburb known for being extremely poor with mainly Roma inhabitants (two participants lived in a particularly notorious set of streets known for crime and poor quality sanitation). The other participant (Adrienn) had moved in with her partner and his family in a nearby town and was relatively secure (and supported) financially. All were either carrying out informal cash-inhand work, on maternity benefits or on the minimum (or very low) wages (most were doing a combination). All participants consider themselves to be 'Hungarian Gypsies', were all born in Dombos, and speak Hungarian only.

\section{Coding: image analysis of local representations}

In coding both sources of photographs, I used the 'picture sources' feature of qualitative data analysis computer software programme NVivo 11 that assists in processing the labelling of the content of each photograph which can then be generated into broader 'themes'. This process of coding is known as 'content analysis' using a semigrounded theory approach to see what categories emerge (Clark-Ibáňez 2007, 177). Through the process of coding both sets of images I could code the content quite easily into categories such as adults, children, types of activities displayed, the state of the living space (e.g. obviously dilapidated, mud streets, rubbish outside etc). This 'categorization' coding gave me a broad idea of what the images were about as a collective. The results can be seen in Table 1. It should be emphasized that this table, whilst focused on numbers and percentages that are compared from the different sources, are not statistically significant and cannot be seen as representative, particularly due to the different number of images from each source. Coding can also be seen as a rather superficial exercise and it is important to remember that "coding produces only another example of situated knowledge that reflects an historical moment and an institutional way of seeing" (Harper 2012, 105). The purpose of counting the categories here is to just give an overview, an illustration of the types of photographs that are prominent when an antistereotype approach is taken. In order to fulfill the article's analytical interest in the 'nonstereotypical' in local representations I draw on literature from contemporary representations of stereotypes of Roma.

\section{Findings and analysis}


The findings and analysis are framed by three of the major themes that have arisen from the findings as shown in Table 1: first, the prevalence of photographing children in both sources; second, the ways Roma adults are portrayed as 'active' or 'passive' in their everyday lives; and third, the notion of 'Roma traditions' represented by the photographs.

\section{TABLE 1 HERE}

\section{Theme one: the prevalence of images of Roma children}

In both sources of images, the camera was overwhelmingly directed at children with a similar proportion of $35 \%$ (source 1) and $42 \%$ (source 2). However, when we look more closely at the sub-themes of this category we can see stark divisions between the two sources. Whilst source 2 (the self-representations) showed all 'children by themselves' looking happy or content in a home or family environment, source 1 (the anti-stereotype photography competition entrants) had under half ( $41 \%$ of the total in this category) looking happy or content, with a similar proportion (36\%) photographed by themselves looking either threatening (in 'gangs') or vulnerable/in danger (e.g. busking or begging in the streets) and then about a fifth (23\%) of the images were children 'wild and free' - roaming around countryside or streets, not necessarily helpless or in danger, but by themselves (mostly in groups) and not in a home or protected environment. Typical shots include children in gangs wandering the streets without guardians; children covered in dirt without shoes; children playing in dirt. Wasteland or rubbish dumps were widely photographed. In contrast in source 2 , the self-made images, Roma babies and children are mostly shown in the home, and often surrounded by or held by adults (see figures 1 and 2).

\section{FIGURE 1 HERE}

\section{Children in a paddling pool at Laci's family home}

\section{FIGURE 2 HERE}

\section{Katalin kissing her son in a 'selfie'}

In wider literature, representing impoverished children by themselves can be used to show the vulnerability of a particular crisis to evoke sympathy and solidarity as what has been termed the "ideal victims" (Höijer 2004, 521-22). However, a criticism of the representations of Roma is that children are often represented by themselves without parental guidance. Rather 
than showing 'vulnerability' this is read by audiences as a lack of family concern and social control (Surdu 2015, 232-235). Roma people are frequently pictured in so-called 'clan' or 'tribe' type structures with lots of children (Pamporov 2012), also linked to an imagined predatory ‘Gypsy’ female sexuality (see Bernáth and Messing 2013, 44-45, Durst 2012, Hasdeu 2012). In many of the Chachipe photographs, Roma children appear to lack the kinship ties of 'ordinary' (unmarked, non-Roma) families. So although children play a major role in the imagined Roma family, safeguarding and nurturing are presumed to be absent. In comparison, the photographs taken by young Roma adults in source 2 emphasise very clearly the central role children take in family life, and how embedded they are in the care of their parents and other adults.

\section{Theme two: Roma adults as 'active' or 'passive'}

The category of 'adults portraits', both source 1 and source 2 have a very similar proportion devoted to this category (around 13\%). However, there are stark differences between the types of images represented. In source 1 (the anti-stereotype competition), whilst a greater proportion (67.5\%) are adults looking happy or in posed portraits (not in dire circumstances), there is still a big proportion (32.5\%) who are pictured looking passive, helpless, begging, sad or in despair - for example adults sitting around in ruined houses or impoverished surroundings as victims of their environments. This contrasts with source 2 , the selfrepresentations, in which the vast majority (91.2\%) are of adults looking happy or posed, with only a few photographs $(8.8 \%)$ in which they look passive or sad. In the category of 'adults doing activities' source 2 (self-representations) show a greater proportion of adults carrying out some type of activity than source 1 (23\% in comparison to $13.9 \%)$.

In source 1 (the Chachipe images) many photographs foreground passive adults -these images seem to be taken of Roma people who are unaware of or unfamiliar with the photographer, e.g. shots of people in the street, from behind or from far away. These are very similar to images of Roma shown in the Hungarian media, in which unique individuality is superseded by a faceless collective. In the media this gives the impression of a faceless gang or mob, a dehumanized group (see Messing \& Bernáth, this volume).

In source 2 (the self-representations), the participants took photos that do reveal some rundown housing and at times small spaces that families live in, but activity in the home 
environment is obvious. Activity is shown in three ways: first, many photographs reveal activity in the backdrop to pictures - people doing paper work, folding curtains, hanging up washing. Second, some photographs foreground work on the home as the main feature of the image: cooking, doing the washing up, renovating or decorating the home (see figures 3, 4 and 5). Third, leisure or traditional activities are captured. In fact, the only photographs in which people could be deemed as 'passive', they are photographed lying down on a bed resting or asleep (rather than sitting around 'doing nothing').

\section{FIGURES 3, 4 \& 5 HERE}

\section{Figure 3. Ágnes' Dad cooking in the kitchen}

\section{Figure 4. István's mother clearing up the kitchen}

\section{Figure 5. Laci and others fixing the gate to their home}

The active/passive representations are worth considering in the wider context of Roma representations. The over-arching theme of activity in the self-representations links to my ethnographic observations - cooking, cleaning and renovating living spaces was a major pasttime of all people I knew in Dombos. I was always humbled by the energy people put into their homes, courtyards and gardens at the weekend. With low wages and old housing stock, being industrious at the weekends was a survival strategy. But there was also a sense of selfworth and status gained in being a good homemaker/good citizen, a particular burden placed on women in Hungary. This harks back to the days when the socialist state would award certificates for 'Clean Yard, Tidy House' ('Tiszta udvar, rendes ház') that meant you could display a placard with the phrase outside of your home. This concept of 'rend' (literally: 'order') is deep-set in Hungarian mentality, and is necessary in order to be seen as acceptable in society, particularly evident in smaller towns and villages. The opposite of 'rendes', 'rendetlen', is not just about being untidy, but also about being disorderly or a trouble-maker or even untrustworthy, and can be used to justify the fate of the poor and marginalised (see Fehérváry 2013, 46-47).

For Roma minorities this concept of 'rendes' is particularly significant. News media analyses show how Roma are frequently visually represented living in dirt and mess, and local authorities still use the concept today to justify punitive measures towards Roma families ${ }^{\mathrm{vi}}$. Being 'rendes' can become an obsession for many Roma households in order to disprove the stereotype. For example, when we were looking through the pictures taken at the family 
home, one mother of a participant saw the photographs of the courtyard (see for example figure 1) and said (with laughter) "oh no it looks like a mess - when you show these pictures tell them we are in the middle of renovating it, otherwise they'll think we're rendetlen Gypsies!!”

In broader discourses, the idea of 'active' or 'passive' adults is an important representation in neoliberal politics. In the West, post-industrial economies have produced tropes of the passive, working-class poor in order to justify welfare reforms that are punitive to the working classes including recent formulations of 'chav' culture in the UK (Skeggs 2004, Tyler 2013). In postsocialist countries the working-class became to be depicted in similar ways post the 1990s transition (Stenning 2005, 984). After the 2008 economic crisis many European countries reformulated their welfare provisions in a way that make explicit or implicit differentiation of the deserving and undeserving poor (Szikra 2014). A very important context of the labour market marginalization of Roma in several Central East European countries are the so called 'activation' programmes. The name itself shows clearly how 'passivity' is seen as the baseline for these communities. Such welfare reform functions as new forms of exclusion which "racialises post-communist class formations, naturalises ethnic differences and maintains, rather than reduces, 'the habits' of the majority to subhumanise or even dehumanise Roma” (van Baar 2012, 1297). Thus Roma are constructed as passive or 'rendetlen' (untidy/untrustworthy) with huge implications for how they are seen, treated and governed.

\section{Theme three: The role of the 'traditional' Roma and 'selfies'}

The category 'traditional people' was quite different in the two sources: source 1 had a number of photographs depicting what can be termed 'Roma traditions' (12.5\%) and the majority of these were representing traditions in a 'noble' sense rather than as 'primitive' (e.g. 'noble' could be images of professional musicians; whilst 'primitive' might be a donkey and cart). In source 2 , however, only a very small proportion (1.1\%) of all the photographs in this category showed Roma as 'traditional people' and these types of traditions were mostly part of a past, rather than a future. For example, in Szabina's home a violin is hung on the wall as decoration, a relic from her grandfather who used to play in a local hotel (figure 6). In István's home a synthesiser can be seen, which when discussed in the photo elicitation interview was found to be used occasionally for weddings or parties, but could only be 
properly played by an uncle. The horses in Adrienn's pictures were also revealed to be a hobby of her father-in-law's in which Adrienn and her partner played no active role ${ }^{\mathrm{vii}}$.

These traditions, whilst important, were often noted by participants as things of the past - a heyday of Gypsy musicians when such music was played in every hotel; a heyday of horse buying and selling when it actually made money. Such traditions may play a more central role in other Roma people's lives, but for these families at this point in time they were emblematic of the past and the older generation.

A feature of the self-representations (source 2) that were not in the Chachipe pictures (source 1) were 'selfies'. The word 'selfie' was the Oxford Dictionaries' word of the year in 2013 (just when this project was carried out), and has become a very popular way of representing oneself on social media sites, with women in particular holding up their smart-phones and snapping themselves in attractive poses or with glamorous backdrops ${ }^{\text {viii }}$. In the selfrepresentations, $11.8 \%$ of the photos (31 out of 262) can be described as 'selfies' and could be seen in five out of the six photo projects, with only Zsófia (with the 7 children) who did not take a selfie, although it should be noted she frequently posts selfies on her Facebook page ${ }^{\mathrm{ix}}$. In these pictures, mostly young women and sometimes men are seen in poses that are taken to deliberately look 'cool' or attractive or loved/loving (with a baby or partner) (see figures 2 and 7).

\section{FIGURES 6 \& 7 HERE}

Figure 6. Szabina's brother in their lounge with their grandfather's violin hung on the wall

\section{Figure 7. Szabina's sister's 'selfie'}

The selfie pictures are potentially important for the representation of Roma people in two ways: first, the act of creating selfies positions these young people in a global culture - thus positioning them as a part of ongoing trends, rather than excluded from them (which is the usual representation). Second, it shows a level of confidence in these young women that scripts on gender and Roma often gloss over or refute. Whilst there is a view that selfies are a form of narcissism, both indulgent and vain, recent literature does counteract that view. 
Selfies can be seen as a potentially powerful means for self-expression, particularly where young women are concerned. In this emerging literature, it is noted how selfies are a way that women can control their representations, resisting "gender melancholia" (Dobson 2014, 2) and forming "new ways" of seeing the female figure in society (Tiidenberg \& Gomez Cruz $2015,19)$. This might be even more relevant for women from poorer, Roma communities who have been practically invisible in public discourses. The selfie could thus represent "articulations of empowerment" (Gavey 2012, 722, quoted in Tiidenberg \& Gomez Cruz $2015,7)$. I would suggest that these selfies or self-portraits were taken as statements of self they indicate that these young Roma people and partnerships are involving themselves in a global self-portrait trend that is playful, individualistic and a statement of being.

\section{Conclusion}

When it comes to representations of Roma, there is a huge gap between the way this minority group is represented in public discourses and their lived realities. Over and over again Roma people are portrayed in dominant society as passive, hapless or dangerous (or traditional or exoticised) in strongly racialised terms. Yet when Roma people get the chance to be the image-makers, we see families interacting and caring, working on the home to improve poor housing, washing, cooking, having fun. This article has shown how, when the everyday is emphasised rather than ethnicity, self representations have the potential to show Roma people much more as active agents in their own lives and circumstances.

Nonetheless, it must be recognised that in an article that uses binary oppositions (Roma/nonRoma; stereotypical/non-stereotypical), albeit with a sensitivity to their inadequacies, it is important not to end up simply offering 'the everyday' as an alternative (but equally loaded) category. As de Certeau writes, questioning categories through a focus on everyday life cannot just be about pushing another category forward, but should be a means to challenge the orthodoxies upon which current representations lie,

[...] far from arbitrarily assuming the privilege of speaking in the name of the ordinary (it cannot be spoken), or claiming to be in that general place (that would be a false “mysticism"), or, worse, offering up a hagiographic everydayness for its edifying value, it is a matter of historicity to the movement which leads analytical procedures back to their frontiers, to the point where they are changed, indeed disturbed, by the ironic and mad banality that speaks in "Everyman"[...] (de Certeau 1984, 5) 
At the same time, it is questionable as to what ordinary images are be useful for at the moment - many Roma people are still mired in poverty and suffer racism on a daily basis therefore surely images that portray their devastating circumstances are required to garner the attention necessary to challenge such inequalities? Many charities and non-governmental and international organisations continue to use such images to shock viewers or readers into action. As Torchin points out, "Human rights organisations hold an almost unshakeable faith in 'awareness': if the world sees abuses, it will respond" (Torchin 2008, 390).

But the repetition of such images can be harmful: organisations end up creating a 'needy subject' (Timmer 2010) that, rather than garnering support, generate racist ideas of hapless, parasitic Roma. Roma activists themselves have raised their voices against always being shown as impoverished and wretched: a group of Bulgarian Roma, for example, wrote a letter to the European Commission, which stated "We demand putting an end to the discriminatory practice of treating all Roma as a socially vulnerable or disadvantaged group. The stigmatization of Roma as 'vulnerable' in EU documents contributes to their forced marginalization" (Tahir et al 2010, quoted in van Baar 2011, 210).

The argument these Bulgarian Roma activists put forward is that such constructions can have a direct effect on the way Roma people are treated. In the Chachipe images, major tropes prevail, for example wild, dangerous children without parental guidance and passive adults. Saminaden et al (2010) argue that such approaches are common towards so-called 'traditional' minorities:

If they are infantilized, then more paternalistic forms of control are required. Indeed, representing traditional people as primitives and savages may have served to justify social control, aggression, exploitation, the cultivation of dependency, and resistance to self-determination (Saminaden et al 2010, 92).

Minorities then appear void of the 'unique human' qualities attributed to the rest of the population, which in turn justifies certain interventions.

I want to emphasise here something very important: the images shown in this article, which prioritise the everyday, do not therefore lead me to the conclusion that these people do not also inhabit structurally significant ethnic or 'racial' positions. I am not saying that they do 
not identify with ethnonyms such as 'Roma' or 'Gypsy', or are exactly the same as everyone else. And I am also not saying that they do not suffer from racism in their everyday lives. As Les Back says:

I am not suggesting for a minute that injustices, inequalities and exclusions are not also alive in the everyday and I have tried to illustrate them here. Rather, I am suggesting people refused to be crushed by those destructive forces (Back 2015, 832)

We need to see that Roma people are not just passive, hapless victims to the dreadful circumstances of poverty and discrimination. We need to challenge that story. As Amanda Wise says: "power and histories of racism are as much a part of the everyday pictures as convivialities and affinities. We are not saying that somehow the everyday is a solution to racism [...] It is [...] adding another layer to our understanding” (Wise quoted in Neal and Murji 2015, 817).

The paucity of everyday, active images in the public sphere points to a huge gap in the public imagination that Roma people can also be 'ordinary'. Encouraging people to represent their everyday experiences, thinking through their similarities as well as their differences, might enable common threads in what Agar calls the "psychic unity of humanity" (Agar 2011, 39). Portraying the 'everyday ethnicity' of Roma is about questioning the established 'norm' from which contemporary negative dominant portrayals continue to be circulated.

\section{References}

Agar, Michael. 2011. "Making sense of one other for another: Ethnography as translation." Language \& Communication 31, 38-47. doi:10.1016/j.langcom.2010.05.001. 
Back, Les. 2015. "Why Everyday Life Matters: Class, Community and Making Lives Livable." Sociology 49(5), 820-836. doi: 10.1177/0038038515589292.

Bernáth, Gábor and Vera Messing. 2013. Pushed to the Edge-Research Report on the Representation of Roma Communities in the Hungarian Mainstream Media, 2011. Budapest: Center for Policy Studies of Central European University.

Brubaker, Rogers. 2006. "Preface". In Brubaker Rogers, Feischmidt Margit, Fox Jon and Grancea Liana Nationalist politics and everyday ethnicity in a Transylvanian Town, xiii-xx. Oxfordshire: Princetown University Press.

Clark-Ibáňez, Marisol. 2007. "Inner-City Children in Sharper Focus: Sociology of Childhood and Photo Elicitation Interviews." In Visual Research Methods. Image, Society and Representation edited by Gregory C. Stanczak, 167-196. London: Sage.

Clayton, John. 2009. "Thinking spatially: towards an everyday understanding of inter-ethnic relations". Social and Cultural Geography. 10(4), 481-498. doi:

$10.1080 / 14649360902853288$

de Certeau, Michel. 1984 (1988 edition used). The Practice of Everyday Life. California: University of California Press.

Dobson, Amy S. 2014. "Performative shamelessness on young women's social network sites: Shielding the self and resisting gender melancholia." Feminism \& Psychology 24(1), 97-114. doi: $10.1177 / 0959353513510651$.

Dyer, Richard. 2002. The matter of images. Essays on representation. Second edition. London: Routledge.

Durst, Judit. 2012. “'What makes us Gypsies, who knows?' Ethnicity and reproduction.” Multi-disciplinary approaches to Romany Studies edited by Michael Stewart and Márton Rövid, 13-34. Budapest: Central European University.

Fehérváry, Krisztina. 2013. Politics in Color and Concrete. Socialist Materialities and the Middle Class in Hungary. Indiana USA: Indiana University Press.

Franklin, Stuart. 2016. The Documentary Impulse. London: Phaidon.

Gay y Blasco, Paloma. 2008. "Picturing 'Gypsies': Interdisciplinary Approaches to Roma Representation”. Third Text 22(3): 297-303. doi: 10.1080/09528820802204235.

Gilroy, Paul. 2002. "The End of Antiracism”. In Race Critical Theories edited by Philomena Essed and David Theo Goldberg, 249-264. Oxford: Blackwells. 
Hall, Stuart. 1990. “Cultural Identity and Diaspora”. In Identity: Community, Culture, Difference edited by Jonathan Rutherford, 222-237. London: Lawrence \& Wishart.

Hall, Stuart. 1997. "The spectacle of the 'other.", In Representation. Cultural representations and signifying practices, edited by Stuart Hall, 223-290. Milton Keynes: Open University Press.

Harris, Roxy. 2006. New Ethnicities and Language Use. Basingstoke: Palgrave Macmillan.

Harper, Douglas. 2002. “Talking about pictures: A case for photo elicitation”. Visual Studies, 17 (1), 13-26.

Harper, Douglas. 2012. Visual Sociology. London: Routledge.

Highmore, Ben. 2011. Ordinary Lives, Studies in the everyday. London: Routledge.

Höijer, Birgitta. 2004. "The discourse of global compassion: The audience and media reporting of human suffering." Media Culture Society 26: 513-31. doi:

$10.1177 / 0163443704044215$.

Imre, Aniko. 2005. "Whiteness in post-socialist Eastern Europe: The time of the Gypsies, the end of race." In Postcolonial whiteness : a critical reader on race and empire, edited by Alfred J. López, x, 261 p. Albany: State University of New York Press.

Mitchell, Claudia. 2011. Doing Visual Research. London: Sage.

Neal, Sarah and Murji, Karim. 2015. "Sociologies of Everyday Life: Editors' Introduction to the Special Issue.” Sociology 49(5), 811-819. doi: 10.1177/0038038515602160.

Pamporov, Alexey. 2012. "The Drunken Swarthy Offenders: The Image of the Roma in the Bulgarian Press in a Pre-election Context'. Население ('Population'), 3 (4), 141-158.

Picker, Giovanni, Greenfields, Margaret and Smith, David. 2015. "Colonial refractions: the 'Gypsy camp' as a spatio-racial political technology. City 19 (5), 741-752. doi: http://dx.doi.org/10.1080/13604813.2015.1071123.

Pierterse, Jan Nedervven. 1992. White on Black. Images of Africa and Blacks in Western Popular Culture. New Haven: Yale University Press.

Robinson, Victoria. 2015. "Reconceptualising the Mundane and the Extraordinary: A lens through which to explore transformation within women's everyday footwear practices". Sociology 49(5), 903-918. doi: 10.1177/0038038515591942.

Rose, Gillian. 2016. Visual Methodologies. An Introduction to Researching with Visual Methods. $4^{\text {th }}$ Edition. London: Sage.

Said, Edward. 1978 (1995 version used). Orientalism. London: Penguin Books.

Saminaden, Annick, Loughnan, Stephen and Haslam, Nick. 2010. "Afterimages of savages: Implicit associations between 'primitives', animals and children." 
Schafft, Kai A. and Kulcsár, László J. 2015. "The Demography of Race and Ethnicity in Hungary." In The International Handbook of the Demography of Race and Ethnicity edited by Sáenz R, Embrick D G, Rodríguez N. P., 553-573. Dordrecht: Springer Netherlands. doi: 10.1007/978-90-481-8891-8_26.

Skeggs, Beverley. 2004. Class, Self, Culture. London: Routledge.

Stanczak, Gregory C. 2007. Visual Research Methods. Image, Society and Representation. London: Sage.

Surdu, Mihai. 2015. Expert Frames: Scientific and Policy Practices of Roma Classification. Budapest: Central European University.

Szalai, Andrea. 2014. "Ideologies of Social Differentiation Among Transylvanian Gabor Roma”. Acta Ethnographica Hungarica, 59(1), 85-112.

Szikra, Dorottya. 2014. "Democracy and welfare in hard times: The social policy of the Orbán Government in Hungary between 2010 and 2014." Journal of European Social Policy 24 (5): 485-500. doi: 10.1177/0958928714545446.

Tiidenberg, Katrin and Cruz Gómez, Edgar. 2015. "Selfies, Image and the Re-making of the Body." Body \& Society. 1-26. Advance online publication. doi: 10.1177/1357034X15592465.

Timmer, Andria, T. 2010. "Constructing the "Needy Subject": NGO Discourses of Roma Need”. Political and Legal Anthropology Review, 33(2), 264-281. doi: 10.1111/j.15552934.2010.01114.x.

Torchin, Leshu. 2008. "Influencing Representation.” Third Text, 22(3), 387-396. doi: $10.1080 / 09528820802204904$.

Trehan, Nidhi, and Kóczé, Angéla. 2009. "Racism, (neo-)colonialism and social justice: the struggle for the soul of the Romani movement in post-socialist Europe." In Racism Postcolonialism Europe, edited by Graham Huggan and Ian Law, 50-74. Liverpool University Press.

Tremlett, Annabel. Forthcoming. "Breakdowns for breakthroughs: how embarrassing, anxiety-ridden, incompetent moments are key to understanding fieldwork." In Learning and Using Languages in Ethnographic Research, edited by Robert Gibb, Annabel Tremlett and Julien Danero-Iglesias. Bristol: Multilingual Matters.

Tremlett, Annabel. 2014. "Making a difference without creating a difference: super-diversity as a new direction for research on Roma minorities". Ethnicities 14(6), 830-848. doi: $10.1177 / 1468796814542183$

Tremlett, Annabel. 2013. “"Here are the Gypsies!” The importance of self-representations \& how to question prominent images of Roma minorities." Ethnic and Racial Studies 36(11), 1706-1725. doi: 10.1080/01419870.2012.669487. 
Tremlett, Annabel. 2009. "Bringing hybridity to heterogeneity in Romani Studies". In Romani Studies, 19(2). 147-168. doi: http://dx.doi.org/10.3828/rs.2009.8.

Tyler, Imogen. 2013. Revolting Subjects. Social Abjection and Resistance in Neoliberal Britain. London: Zed Books.

van Baar, Huub. 2011. "Europe's Romaphobia: Problematization, securitization, nomadization." Environment and Planning D: Society and Space 29(2): 203-12. doi:10.1068/d2902ed1.

van Baar, Huub. 2012. "Socio-Economic Mobility and Neo-Liberal Governmentality in PostSocialist Europe: Activation and the Dehumanisation of the Roma." Journal of Ethnic and Migration Studies 38 (8): 1289-1304. doi:10.1080/1369183X.2012.689189.

Vermeersch, Peter. 2006. The Romani Movement. Minority Politics \& Ethnic Mobilization in Contemporary Central Europe. Oxford: Berghahn Books.

Willems, Wim. 1997. In Search of the True Gypsy. From Enlightenment to Final Solution. London: Frank Cass. 
'Roma' is used frequently as an umbrella term for any groups associated with Roma, Gypsy or Traveller and so on. It can also be used as an ethnonym to denote a group of people with a particular 'Rom' ethnic identity which includes speaking a particular Romani language (for further discussion on the politics of Roma identity, ethnicity and labelling see Tremlett 2014). I justify the use of 'Roma' here as a broad category as I am looking at broad (often crude) representations of 'Roma'/'non-Roma'. However 'Hungarian Gypsy' ('magyarcigány') was used by local people in the town where I carried out my research, including people from Gypsy backgrounds, who did not usually recognise the term 'Roma' for themselves. 'Roma' minorities (Hungarian Gypsies make up one group) are said to make up about $4-6 \%$ of the population of Hungary, although this is likely to be an underestimation (see Schafft and Kulcsár 2015).

ii Many thanks to the three anonymous reviewers for their excellent suggestions that really helped to develop this article. I am also grateful to my two co-editors for their insightful comments in the course of writing and editing, and to the audience at the Challenging Romaphobia Symposium (Tuesday November $3^{\text {rd }} 2015$, University of Brighton) for the lively discussions. Thanks also to University of Portsmouth colleagues Dr Stephen Harper and Dr Sophia Wood for their wise comments and advice.

iii This research was carried out thanks to a British Academy Small Grant awarded 2012-2014 (SG112414). I carried out all my research in Hungarian, a language I have been learning since 2000. In 2008 I passed the advanced level Hungarian language oral and written exams (Hungarian State Accredited Language Examination, 'Level C1'). For more discussion on my status as 'less-than-fluent' in the language and cultural practices of my research participants see Tremlett 2009 and Tremlett, forthcoming.

iv Verzio website. Accessed February 20 ${ }^{\text {th }}$ 2017: http://www.verzio.org/2007/exhibition/index.html

$\checkmark \quad$ Ethical consent was sought from the participating young people in 2013, in accordance with UK ethical guidelines. All names of people and places have been changed to protect some anonymity. However, faces can be seen in the images. This was explained to each participant orally as well as in written form, with the options to remove photographs from the research altogether, or have photographs described rather than published in publications if the participant so wished. Consent was given to show the images in this article.

vi See the case of a local authority in Hungary who only allowed benefits to those Roma families who could prove their cleanliness in the home: 'Tiszta udvar, rendes ház' ['Clean Yard, Tidy House'], published on the Jogtalanul ['Unlawfully'] website, December 03 2012. Accessed April 14 ${ }^{\text {th }}$ 2016: http://jogtalanul.blog.hu/2012/03/12/tiszta_udvar_rendes_haz_10

I was surprised that even his son, Adrienn's partner Gábor, said he didn't know how to ride well, and Adrienn said he only went to pose with them for the picture, he was actually quite scared of them. Gábor's father chastised him for choosing the skinny horse for the picture as it had been ill. Gábor said he hadn't even noticed - further showing his lack of interest in his father's hobby.

viii . Hungary has not escaped the trend, creating the 'Hunglish' word 'szelfi'. Even the Prime Minister, Viktor Orban, posted a 'szelfi' of himself with his daughters on Facebook in 2014 prior to the election, and the picture gained a lot of media coverage, precisely because it was a 'szelfi' with coverage mocking Orban's serious expression and attempts as this new trend http://444.hu/2014/03/15/orban-szelfi444/

ix In this group there are a few pictures that are posed self-portraits rather than strictly selfies (4 out of the 31). I felt these should still be in this category as they are very deliberately posed and appear to do the same 'job' as selfies (i.e. a flattering or posing-to-look-'cool' image of the person in question). 